\title{
Grading of gastric foveolar-type dysplasia in Barrett's esophagus
}

\author{
Dipti Mahajan ${ }^{1}$, Ana E Bennett ${ }^{1}$, Xiaobo Liu ${ }^{2}$, James Bena² and Mary P Bronner ${ }^{1}$ \\ ${ }^{1}$ Department of Anatomic Pathology, Cleveland Clinic Foundation, Cleveland, OH, USA and ${ }^{2}$ Department of \\ Quantitative Health Sciences, Cleveland Clinic Foundation, Cleveland, OH, USA
}

\begin{abstract}
Dysplasia is the gold standard biomarker of cancer risk in Barrett's esophagus, but its diagnosis remains difficult. This is due in part to its multitude of histological appearances. One aspect receiving little attention concerns gastric-type Barrett's dysplasia, which is distinctly different from the well-established intestinal variant. Recognition of gastric-type dysplasia and development of separate grading criteria are required. The prevalence, diagnostic criteria, and natural history of gastric-type Barrett's dysplasia were systematically evaluated in 1854 endoscopic biopsies from a cohort of 200 consecutive Barrett's dysplasia patients. Goblet cells were present in all cases, confirming the utility of this defining feature of Barrett's esophagus. The prevalence of Barrett's gastric-type dysplasia was $15 \%$ at the patient level (30 of 200 patients) and $20 \%$ at the biopsy level (166 of 852 dysplastic biopsies). Gastric-type dysplasia uniformly showed non-stratified, basally oriented nuclei as the major criterion for distinguishing it from intestinal-type Barrett's dysplasia. As such, loss of nuclear polarity, as the most objective criterion to distinguish intestinal-type low- and high-grade dysplasia, cannot be applied to gastric-type dysplasia. Rather, discriminatory features included increased nuclear size with a high-grade dysplasia cutoff by receiver operating characteristic $(\mathrm{ROC})$ analysis approximating 3-4 times the size of a mature lymphocyte, providing an optimal sensitivity, specificity, and area under the curve of 0.78 , 0.90 , and 0.90 (95\% Cl: $(0.87,0.93))$, respectively. Crowded, irregular glandular architecture $(P<0.001)$ was more common in high-grade lesions $(P<0.001)$, as was eosinophilic and oncocytic cytoplasm relative to the mucinous cytoplasm $(P<0.001)$, prominent nucleoli $(P<0.001)$, mild nuclear pleomorphism $(P<0.001)$, and villiform architecture $(P<0.001)$. During follow-up, $64 \%$ (7 of 11) of patients with pure gastric and $26 \%$ (5 of 19$)$ with mixed gastric and intestinal dysplasia underwent neoplastic progression. The recognition of Barrett's gastric-type dysplasia and use of the proposed grading criteria should promote better diagnostic classification of the Barrett's neoplastic spectrum.
\end{abstract}

Modern Pathology (2010) 23, 1-11; doi:10.1038/modpathol.2009.147; published online 16 October 2009

Keywords: Barrett's esophagus; gastric-type dysplasia; intestinal-type dysplasia; low-grade dysplasia; high-grade dysplasia; intra-mucosal carcinoma

Barrett's esophagus predisposes to esophageal adenocarcinoma, with an estimated risk that approaches 125 times that of the general population. ${ }^{1-3}$ The histological diagnosis of dysplasia in endoscopic biopsies remains the gold standard marker for early diagnosis and cancer prevention in Barrett's esophagus. Precancerous dysplasia in Barrett's esophagus has two distinct histological subtypes, paralleling what occurs in

Correspondence: Professor MP Bronner, MD, Department of Anatomic Pathology, Cleveland Clinic Foundation, L-25, 9500 Euclid Avenue, Cleveland, OH 44195, USA.

E-mail: bronnem@ccf.org

Received 29 June 2009; revised and accepted 31 August 2009; published online 16 October 2009 gastric epithelial dysplasia. ${ }^{4-6}$ The far more common 'adenomatous' or intestinal-type dysplasia in Barrett's esophagus is widely recognized. However, the second category of Barrett's dysplasia, namely, gastric foveolar-type dysplasia, has gone virtually unrecognized in the Barrett's literature. It is poorly characterized with regard to its prevalence, histological features, natural history, and especially its diagnostic criteria. ${ }^{4-6}$ To our knowledge, no grading criteria have been published. Owing to its distinctly different morphology, gastric foveolar-type dysplasia does not readily conform to standard intestinaltype dysplasia diagnostic or grading criteria. As such, it can pose serious difficulties for the diagnostic pathologist. This problem is further magnified in Barrett's esophagus by the major 
clinical management consequences of esophagectomy with its well-established morbidity and mortality. ${ }^{7}$

This study evaluates the prevalence of, morphological criteria for, and natural history of gastric foveolar-type dysplasia in Barrett's esophagus, using a consecutive patient cohort diagnosed with Barrett's dysplasia at the Cleveland Clinic. On the basis of systematic assessment of the morphological features in combination with longitudinal followup validation, we define for the first time histological grading criteria for gastric foveolar-type dysplasia in Barrett's esophagus.

\section{Materials and methods}

\section{Patients}

This research was approved by the Cleveland Clinic Institutional Review Board. Consecutive patients with dysplastic Barrett's esophageal mucosal biopsies were identified in the pathology archives between the period of January 2006 to January 2008. Inclusion criteria required at least one neoplastic (dysplasia and/or carcinoma) Barrett's biopsy in each patient. The intestinal vs gastric foveolar types of dysplasia were not specified in the original diagnoses on file for any of the consecutive cases comprising this study. Rather, these subtypes were further characterized as the main goal of this study. Only primary Cleveland Clinic patients were included in the study. Extramural pathology consultation cases were excluded in an attempt to reduce referral bias. Barrett's esophagus was defined using the American College of Gastroenterology definition, requiring both endoscopic (glandular mucosa in the anatomic tubular esophagus) and histological (intestinal metaplasia with goblet cells) parameters. ${ }^{8}$ Using these criteria, a total of 1854 endoscopic biopsies from a cohort of 200 consecutive Barrett's dysplasia patients were selected for the study.

\section{Histological Evaluation}

All biopsies were routinely fixed in $10 \%$ alcoholic formalin, processed as four biopsies per block into $5 \mu \mathrm{m}$ step and serial sections, and stained with hematoxylin and eosin. All the biopsies were diagnosed by simultaneous consensus agreement of the two gastrointestinal pathologists and pathology resident authors (AEB, MPB and DM), using a multiheaded BX61 Olympus microscope. Each individual biopsy was assessed for dysplasia. Dysplasia was restrictively defined as unequivocal neoplastic epithelium confined to the luminal side of the basement membrane. ${ }^{6}$ Dysplasia was distinguished from reactive or regenerative abnormalities induced by inflammatory injury. ${ }^{6}$ The presence of goblet cells was ascertained in every biopsy. Finally, each biopsy was analyzed for intestinal-type (adenomatous) and/or gastric-type (foveolar) dysplasia.

Intestinal-type dysplasia in Barrett's esophagus was defined by stratification of enlarged, elongated to pleomorphic and hyperchromatic nuclei with glandular crowding. The categories of neoplasia, including negative for dysplasia, indefinite for dysplasia, low-grade dysplasia, high-grade dysplasia, intramucosal carcinoma, and adenocarcinoma with at least submucosal invasion, were defined according to the published criteria of Montgomery et $a l^{6}$ and Downs-Kelly et $a l^{9}{ }^{9}$ These criteria refer only to the intestinal variant of dysplasia in Barrett's esophagus.

Gastric dysplasia in Barrett's esophagus was systematically evaluated for the following histological features in an attempt to better define this variant of dysplasia and its useful grading criteria: (1) nuclear stratification, (2) complexity and crowding of dysplastic glands, (3) glandular or villiform architecture, (4) mucinous, oncocytic, or eosinophilic cytoplasm, (5) nuclear pleomorphism, (6) nuclear size relative to small, mature lymphocytes within the epithelium or the lamina propria in the most abnormal field at high magnification $(\times 400$, actual field size $0.25 \mathrm{~mm}^{2}$ ), and (7) nucleoli. Criteria for gastric-type dysplasia grade were developed from the analysis of above morphological data into the parallel subcategories that are already existing for intestinal-type Barrett's dysplasia (negative, indefinite, low-grade, high-grade, intramucosal adenocarcinoma, and adenocarcinoma with at least submucosal invasion).

All available retrospective and prospective longitudinal esophageal biopsies and surgical resections were examined from patients with gastric-type dysplasia, either pure or admixed with intestinaltype dysplasia at other sites within the Barrett's segment.

\section{Statistical Analysis}

Continuous measures were described by their means, standard deviations, and percentiles. Categorical measures were summarized using frequencies and percentages. Pearson's $\chi^{2}$ test or Fisher's exact test was used to assess the association between categorical outcomes of interest. For the evaluation involving the ordinal outcome of interests, MantelHaenszel $\chi^{2}$ tests or Cochran-Armitage tests were carried out to measure trends across ordinal levels. Spearman's correlation coefficients were estimated in order to study the association between the ordinal outcomes of interest. The majority of the analysis was performed at the biopsy and patient levels. Receiver operating characteristic (ROC) curve analysis using logistic regression was carried out to assess the prediction ability of identifying highgrade dysplasia combined with intramucosal carcinoma (gastric-type) using nuclear size (relative to a 
small mature lymphocyte). All tests were carried out at a significance level of 0.05. SAS 9.2 software (SAS Institute, Cary, NC, USA) was used for all analyses.

\section{Results}

\section{Patient Population and Study Material}

A total of 200 consecutive Barrett's patients with dysplasia were selected for study during the period from January of 2006 through January of 2008. A total of 559 blocks encompassing a total of 1854 biopsies were reviewed. The age for all patients combined $(n=200)$ ranged from 30 to 89 years (mean 65; median 66), with a male-to-female ratio of 3.3:1. The patients with pure gastric-type dysplasia $(n=11)$ ranged in age from 57 to 86 years (mean 73 ; median 73), with a male-to-female ratio of $2.7: 1$. The patients with mixed gastric and intestinal dysplasia $(n=19)$ ranged in age from 55 to 84 years (mean 71.7; median 74), with a male-to-female ratio of 2.2:1. Those with pure intestinal-type dysplasia $(n=170)$ ranged in age from 30 to 89 years (mean 64 ; median 64), with a male-to-female ratio of 3.6:1. Overall, therefore, patients with gastric-type dysplasia were approximately one decade older than those with intestinal-type dysplasia and had increased numbers of women.

\section{Goblet Cells}

Despite the focus of this study on the gastric-type cell population in Barrett's esophagus, goblet cells were still identified in all dysplastic biopsies from all $200(100 \%)$ patients. This further validates the use of goblet cells as the defining histological feature for Barrett's esophagus, regardless of whether it harbors gastric or intestinal-type dysplasia.

\section{Prevalence of Barrett's Gastric-Type Dysplasia}

Patient level

The prevalence of pure gastric-type dysplasia at the patient level was 6\% (11 of 200 patients). The prevalence of mixed intestinal and gastric-type dysplasia was $10 \%$ (19 of 200 patients). The prevalence pure intestinal-type dysplasia was $85 \%$ (170 of 200 patients).

\section{Biopsy level}

Of the 1854 total biopsies in this 200 patient cohort, a subset of 1002 was negative for dysplasia and a total of 852 biopsies showed dysplasia. Of those with dysplasia, the prevalence of biopsies showing gastric-type dysplasia was $20 \%$ of biopsies (166 of 852).

\section{Histological Features for Defining Gastric-Type Dysplasia}

The 166 biopsies showing gastric-type dysplasia were further subclassified on the basis of the following seven histological features.

\section{Nuclear Stratification}

All $166(100 \%)$ biopsies with gastric-type dysplasia in this patient cohort had non-stratified nuclei throughout the full thickness of the mucosa (Figures 1-3). Intestinal-type dysplasia, on the other hand, was characterized by stratified nuclei.

\section{Complexity of Glands}

Complexity of glands was assessed at low magnification to determine whether they were crowded or uncrowded, assessing both the gland-to-lamina propria stromal ratio and gland shape. In the nondysplastic setting, the glands were characteristically round with little budding and were surrounded by abundant lamina propria. Dysplastic glands were sometimes arranged in an uncrowded pattern with modest amounts of encompassing lamina propria $(22 \%)$ (Figure 1). In these cases, cytological features established the diagnosis of dysplasia. Crowding of cytologically abnormal glands was a further feature of dysplasia (Figure 2). Cribriforming of glands or dilated glands with necrotic luminal debris were considered severe architectural abnormalities (Figure 3). In the present cohort, $78 \%$ of the biopsies with gastric-type dysplasia had a crowded morphology.

\section{Villous or Glandular Architecture}

A total of $94 \%$ of the biopsies with gastric-type dysplasia (156 of 166 biopsies) had a glandular architecture and 6\% were villiform (10 of 166 biopsies).

\section{Cytoplasm}

The cytoplasmic characteristics were subdivided into mucinous, oncocytic (with bright, eosinophilic cytoplasmic granules) and eosinophilic non-granular cytoplasm. In our study, $45 \%$ of the biopsies with gastric-type dysplasia had mucinous cytoplasm, $18 \%$ of the biopsies had oncocytic cytoplasm and $37 \%$ of the biopsies had eosinophilic cytoplasm (Figures 1-3).

\section{Nuclear Pleomorphism}

Uniform, monomorphic nuclei were assessed to lack pleomorphism. Even the most pleomorphic nuclei in gastric-type dysplasia were substantially so less 


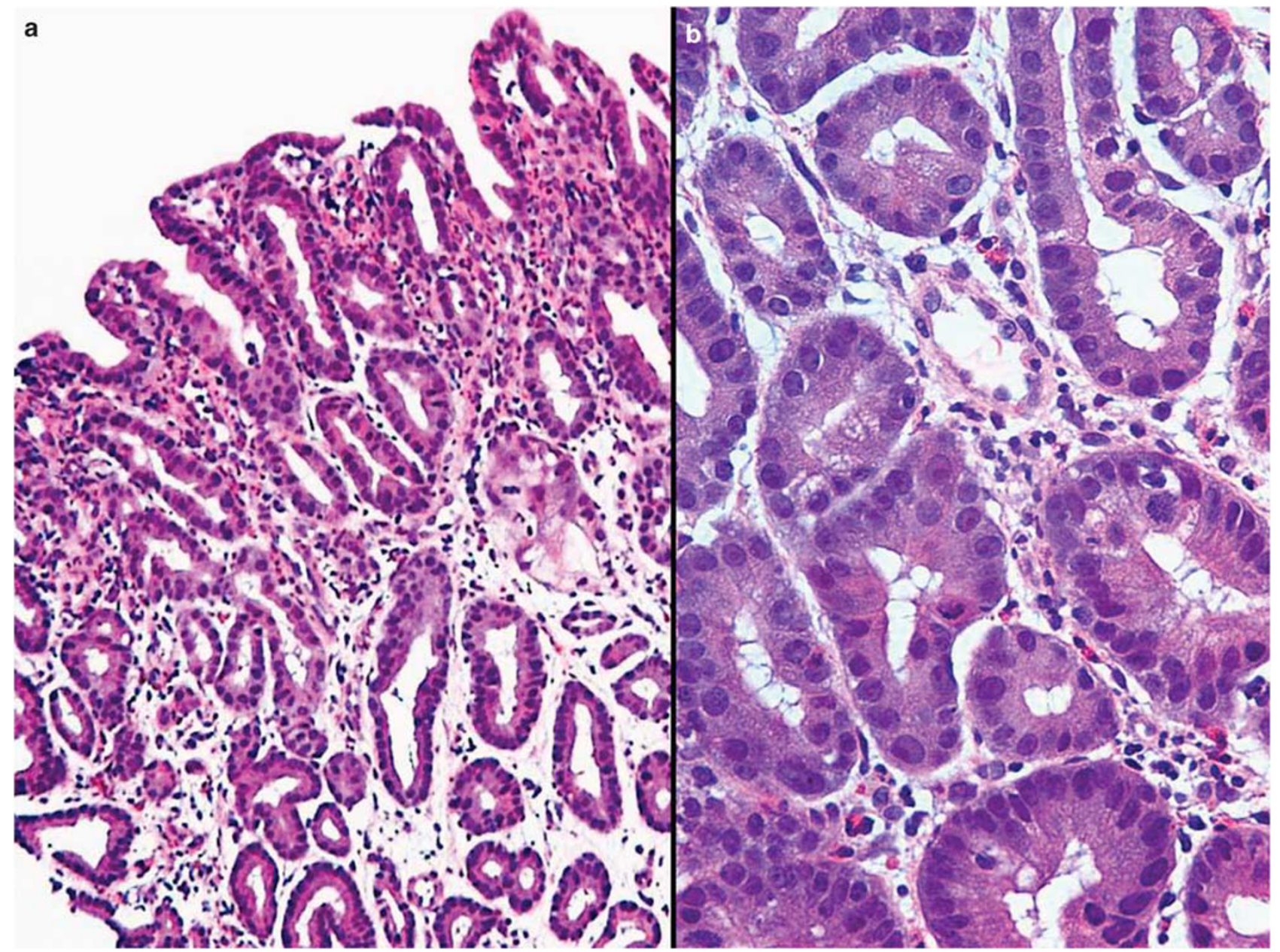

Figure 1 (a) Low-grade gastric-type dysplasia in Barrett's esophagus. The biopsy shows monomorphic cytology and architecture, with uncrowded glands and uniform monolayered, non-stratified nuclei. The changes occupy the full thickness of the mucosa. There is no significant nuclear stratification or loss of nuclear polarity (H\&E, original magnification $\times 100)$. (b) High-power view of low-grade gastrictype dysplasia in Barrett's esophagus depicting the round-to-oval monolayered nuclei with prominent nucleoli that are enlarged to at least 2-3 times that of interspersed small, mature stromal lymphocytes (H\&E, original magnification $\times 400$ ).

than the maximum pleomorphism observed in the intestinal-type dysplasia counterparts. In other words, the spectrum of pleomorphism was narrower in gastric-type dysplasia than intestinal-type dysplasia. In our study, $65 \%$ of gastric dysplasia biopsies had uniform nuclei (Figure 1) and 35\% depicted largely mild nuclear pleomorphism (Figure 2).

\section{Nuclear Size}

Nuclear size was assessed at high magnification $(\times 400)$ in the most abnormal microscopic field. Nuclear size was measured relative to small, mature lymphocytes, a common stromal or intraepithelial cell encountered in Barrett's biopsies. This relative size comparison controlled for the vagaries of fixation and tissue processing that can change the absolute nuclear size for different slide preparations. On average, Barrett's gastric-type glands that were negative for dysplasia were 1-1.5 times the size of a small, mature lymphocyte. About $45 \%$ (74 of 166) of biopsies with gastric-type dysplasia were 2-3 times the size of a small, mature lymphocyte (Figure 1), and 55\% (91 of 166) biopsies were about 3-4 times the size of a small, mature lymphocyte nucleus (Figures 2 and 3).

\section{Nucleoli}

Nucleoli in epithelial cell nuclei were assessed in the most abnormal field. A total of $84 \%$ of the biopsies with gastric-type dysplasia had prominent nucleoli (Figures $1 \mathrm{~b}$ and $2 \mathrm{~b}$ ) and $16 \%$ of the biopsies did not show nucleoli.

\section{Composite Analysis of Histological Features Relative to Dysplasia Grade}

In this analysis, the above seven histological features were examined relative to the various grades of gastric-type dysplasia. Grade was assessed 


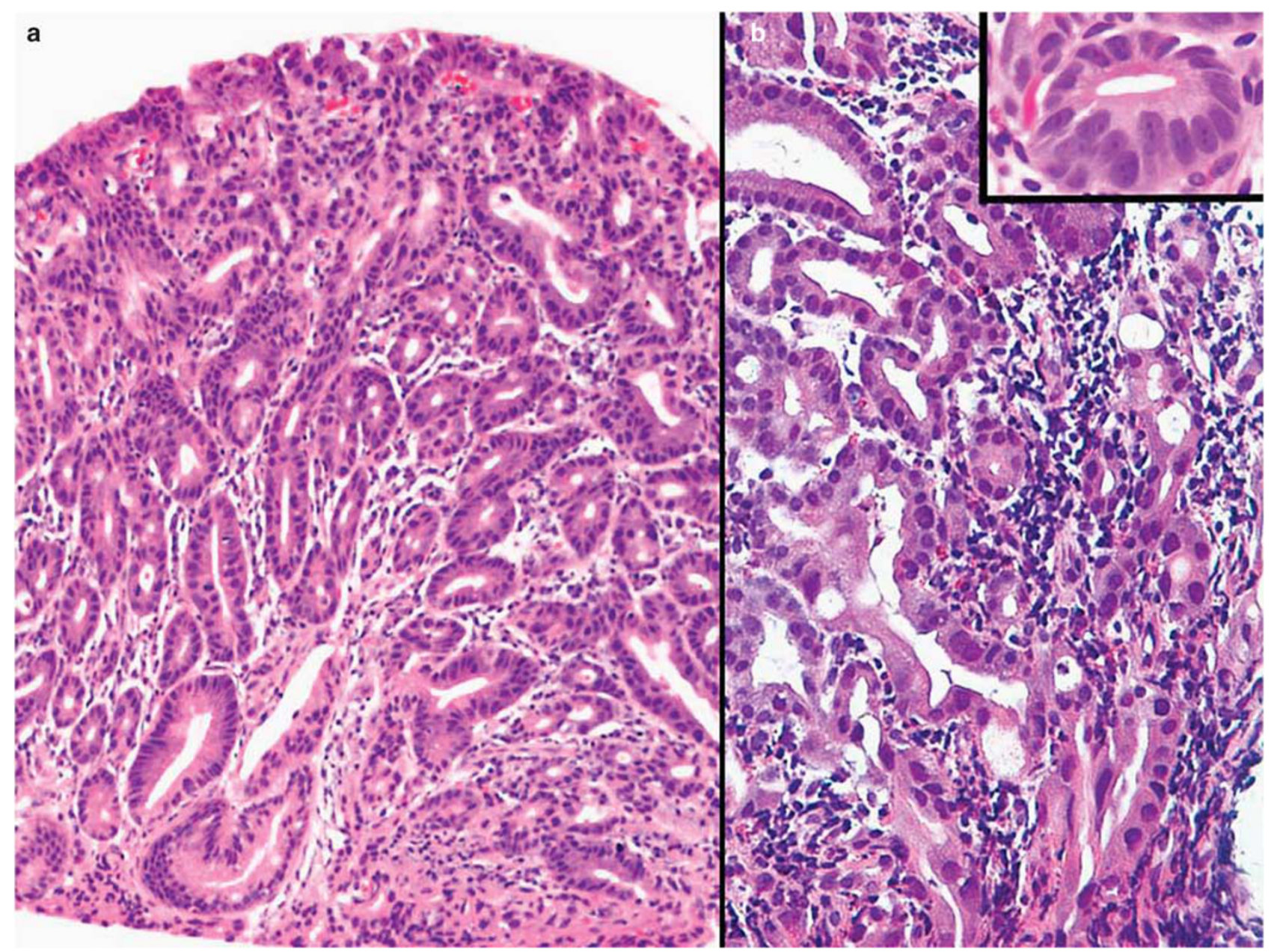

Figure 2 (a) High-grade gastric-type dysplasia in Barrett's esophagus. Full mucosal thickness and crowded, back-to-back arrangement of glands is present, with basally located and monolayered nuclei. The uniformity of the epithelial proliferation engenders a clonal appearance $(\mathrm{H} \& \mathrm{E}$, original magnification $\times 100)$. (b) High-power view of high-grade gastric-type dysplasia in Barrett's esophagus showing crowded glands with increased but still mild nuclear pleomorphism and maintenance of a basal, monolayered arrangement. Note that the enlarged dysplastic nuclei are at least 3-4 times the size of interspersed small, mature lymphocyte nuclei. The inset depicts the enlarged nuclei and prominent nucleoli $(\mathrm{H} \& \mathrm{E}$, original magnification $\times 400)$.

according to the spectrum of pathological change present and the experience of the pathologist authors, as no published criteria exist. The histological findings across the various grades of gastrictype dysplasia are summarized in Table 1. All biopsies with gastric-type dysplasia of any grade had non-stratified nuclei. In comparison with mucinous cytoplasm, eosinophilic and oncocytic cytoplasm were more common in high-grade lesions, as were prominent nucleoli, nuclear pleomorphism, crowded and pleomorphic architecture $(P<0.001$; Table 1 and Figures 1-3). The majority of the gastric-type biopsies showed a glandular architecture. However, villiform morphology was significantly associated with high-grade dysplasia and intramucosal adenocarcinoma $(P<0.001)$. The majority of biopsies with gastrictype low-grade dysplasia (78\%) had nuclei that were 2-3 times the size of a small, mature lymphocyte, whereas the majority of gastric-type high-grade dysplasia $(73 \%)$ and intramucosal adenocarcinoma $(100 \%)$ biopsies had nuclei that were 3-4 times the size of a small, mature lymphocyte nucleus $(P<0.001$; Table 1). An ROC curve was plotted to determine the ability of nuclear size to distinguish negative and low-grade dysplasia from high-grade dysplasia and intramucosal adenocarcinoma. Nuclear size with an optimal cutoff of 3-4 times the size of a small, mature lymphocyte by ROC analysis provided optimal sensitivity, specificity, and area under the curve of $0.78,0.90$, and 0.90 (95\% CI: $(0.87,0.93))$, respectively. A nuclear size of 3-4 times the size of a small, mature lymphocyte or above was predictive of high-grade dysplasia and intramucosal adenocarcinoma in our study, whereas a nuclear size below this was predictive of indefinite for dysplasia and low-grade dysplasia (Figure 4). 


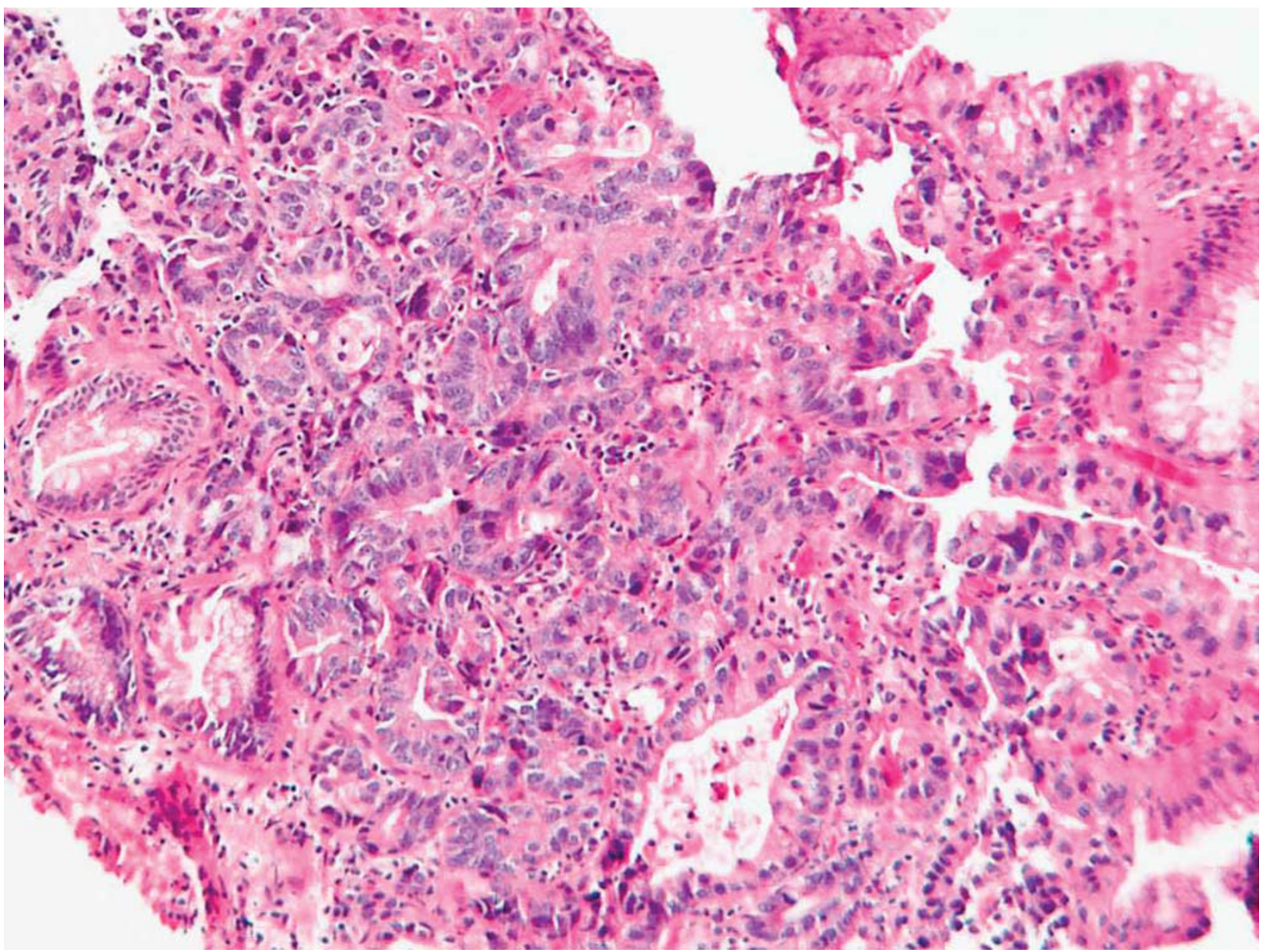

Figure 3 Intramucosal carcinoma, gastric-type. The biopsy shows a crowded, back-to back arrangement of glands in a never-ending, complex growth pattern. Some of the glands show necrotic luminal debris. Note that these glands still show only relatively mild pleomorphism $(\mathrm{H} \& \mathrm{E}$, original magnification $\times 100)$.

\section{Natural History of the Patients with Gastric-Type Dysplasia $(n=30)$}

Longitudinal follow-up of the 30 patients with gastric-type dysplasia in this study (comprising of 11 patients with pure gastric-type dysplasia and 19 patients with mixed gastric and intestinal-type dysplasia) were reviewed from all previous or subsequent endoscopic biopsies or esophagectomies. Follow-up procedures were identified over a retrospective period of 6 years (January 2000 to January 2006) and a prospective period of 1.5 years (January 2008-May 2009) for a total range of up to 8 years of follow-up. The total number of procedures in these 30 patients over this time varied from 1 to a maximum of 13 .

Patients who progressed to a higher grade of dysplasia or carcinoma $(n=12)$

Of the $11(64 \%)$ patients, 7 with pure gastric-type dysplasia and 5 of the $19(26 \%)$ patients with mixed dysplasia progressed to a higher grade of dysplasia during longitudinal analysis over a total period of 8 years (Figure 5).

Patients whose diagnoses remained unchanged $(n=13)$

One patient with gastric-type intramucosal adenocarcinoma underwent subsequent resection. The esophagectomy specimen showed the same diagnosis. The diagnosis also remained unchanged in the other 12 patients with mixed gastric and intestinaltype dysplasia. Eight of these patients had highgrade dysplasia as their most advanced diagnosis (over a range of follow-up from 1-6 years) and four had intramucosal adenocarcinoma as their most advanced diagnosis on both their initial biopsy and subsequent endoscopic mucosal resection, after which they have remained free of dysplasia for a range of follow-up from 0 to 3 years.

Patients lost to follow-up $(n=5)$

The remaining three patients with pure gastric-type dysplasia and two with mixed gastric and intestinaltype dysplasia were lost to follow-up. 
Table 1 Distribution of cytoarchitectural features among varying grades of gastric-type neoplasia in Barrett's esophagus

\begin{tabular}{|c|c|c|c|c|c|c|}
\hline $\begin{array}{l}\text { Histological } \\
\text { feature }\end{array}$ & $\begin{array}{c}\text { Negative for } \\
\text { dysplasia } \\
\text { (no.) (\%) } \\
\mathrm{N}=80\end{array}$ & $\begin{array}{c}\text { Indefinite for } \\
\text { dysplasia } \\
\text { (no.) (\%) } \\
\mathrm{N}=1\end{array}$ & $\begin{array}{c}\text { Low-grade } \\
\text { dysplasia } \\
\text { (no.) }(\%) \\
\mathrm{N}=68\end{array}$ & $\begin{array}{c}\text { High-grade } \\
\text { dysplasia } \\
\text { (no.) (\%) } \\
\mathrm{N}=77\end{array}$ & $\begin{array}{c}\text { Intramucosal } \\
\text { carcinoma } \\
\text { (no.) }(\%) \\
\mathrm{N}=20\end{array}$ & P-value \\
\hline \multicolumn{7}{|c|}{ Nuclear stratification } \\
\hline Stratified & $0(0)$ & $0(0)$ & $0(0)$ & $0(0)$ & $0(0)$ & \multirow[t]{2}{*}{ NA } \\
\hline Non-stratified & $80(100)$ & $1(100)$ & $68(100)$ & $77(100)$ & $20(100)$ & \\
\hline \multicolumn{7}{|c|}{ Complexity of glands } \\
\hline Crowded & $0(0)$ & $0(0)$ & $33(49)$ & $77(100)$ & $20(100)$ & \multirow[t]{2}{*}{$<0.001^{\mathrm{a}}$} \\
\hline Uncrowded & $80(100)$ & $1(100)$ & $35(52)$ & $0(0)$ & $0(0)$ & \\
\hline \multicolumn{7}{|l|}{ Architecture } \\
\hline Villiform & $0(0)$ & $0(0)$ & $0(0)$ & $6(8)$ & $4(20)$ & \multirow[t]{2}{*}{$<0.001^{\mathrm{a}}$} \\
\hline Glandular & $80(100)$ & $1(100)$ & $68(100)$ & $71(92)$ & $16(80)$ & \\
\hline \multicolumn{7}{|l|}{ Cytoplasm } \\
\hline Mucinous & $80(100)$ & $1(100)$ & $47(69)$ & $18(23)$ & $9(45)$ & \multirow[t]{3}{*}{$<0.001^{\mathrm{b}}$} \\
\hline Oncocytic & $0(0)$ & $0(0)$ & $4(6)$ & $23(30)$ & $3(15)$ & \\
\hline Eosinophilic & $0(0)$ & $0(0)$ & $17(25)$ & $36(47)$ & $8(40)$ & \\
\hline \multicolumn{7}{|c|}{ Nuclear pleomorphism } \\
\hline Pleomorphic & $0(0)$ & $0(0)$ & $9(13)$ & $32(42)$ & $17(85)$ & \multirow[t]{2}{*}{$<0.001^{\mathrm{a}}$} \\
\hline Uniform & $80(100)$ & $1(100)$ & $59(87)$ & $45(58)$ & $3(15)$ & \\
\hline \multicolumn{7}{|c|}{ Nuclear size relative to small mature lymphocyte (times) } \\
\hline $1-1.5$ & $80(100)$ & $1(100)$ & $0(0)$ & $0(0)$ & $0(0)$ & \multirow[t]{3}{*}{$<0.001^{\mathrm{c}}$} \\
\hline $2-3$ & $0(0)$ & $0(0)$ & $53(78)$ & $21(27)$ & $0(0)$ & \\
\hline $3-4$ & $0(0)$ & $0(0)$ & $15(22)$ & $56(73)$ & $20(100)$ & \\
\hline \multicolumn{7}{|l|}{ Nucleoli } \\
\hline Absent & $80(100)$ & $0(0)$ & $27(40)$ & $0(0)$ & $0(0)$ & \multirow[t]{2}{*}{$<0.001^{\mathrm{a}}$} \\
\hline Present & $0(0)$ & 1 (100) & $41(60)$ & 77 (100) & 20 (100) & \\
\hline
\end{tabular}

$N$, total number of patients diagnosed with a particular grade of dysplasia; $n$, number of patients per histologic feature; \%, percentage of patients per histological feature.

${ }^{\mathrm{a} C o c h m a n-A m i t a g e ~ t r e n d ~ t e s t . ~}$

bisher's exact test.

${ }^{\mathrm{c}}$ Mantel-Haenszel $\chi^{2}$ test.

\section{Most Advanced Diagnosis per Patient Comparing Gastric and Intestinal-Type Dysplasia}

The prevalence of the most advanced diagnosis in gastric-type vs intestinal-type dysplasia was significantly different and higher for gastric dysplasia at all grades at the patient level ( $P$-values: 0.001 for lowgrade dysplasia, 0.03 for high-grade dysplasia, and 0.003 for intramucosal adenocarcinoma using two sample $t$-test). The majority of patients within this cohort with intestinal-type dysplasia were graded at the lower end of the dysplasia spectrum, with indefinite for dysplasia and low-grade dysplasia comprising the majority at a total of $67 \%$. In contrast, the majority of the patients with gastrictype dysplasia in this cohort or $77 \%$ had diagnoses of high-grade dysplasia or intramucosal adenocarcinoma as their most advanced lesions. In patients with mixed gastric and intestinal-type dysplasia (19 of 200 patients), 13 patients had gastric-type dysplasia as their worst diagnosis (1 low-grade dysplasia, 7 high-grade dysplasia, and 5 intramucosal adenocarcinoma), 1 had intestinal dysplasia (intramucosal adenocarcinoma), and 5 had the same histological grade of gastric and intestinal-type dysplasia (1 low-grade dysplasia, 3 high-grade dysplasia, and 1 intramucosal adenocarcinoma).

\section{Discussion}

Barrett's metaplastic epithelium contains a mixture of several cell types, namely goblet cells, pseudoabsorptive intestinal-type cells and gastric foveolartype cells, so that it should come as no surprise that dysplasia arising from this heterogeneous cell background might also possess different morphologies requiring different criteria. The gastric foveolar variant of dysplasia is one distinctive morphologic variant of Barrett's dysplasia that adds considerably to its heterogeneity and classification difficulties, particularly because there are no published diagnostic criteria. Recognition of gastric-type Barrett's dysplasia as a diagnostic entity, as well as the creation of grading criteria for this subtype, is 


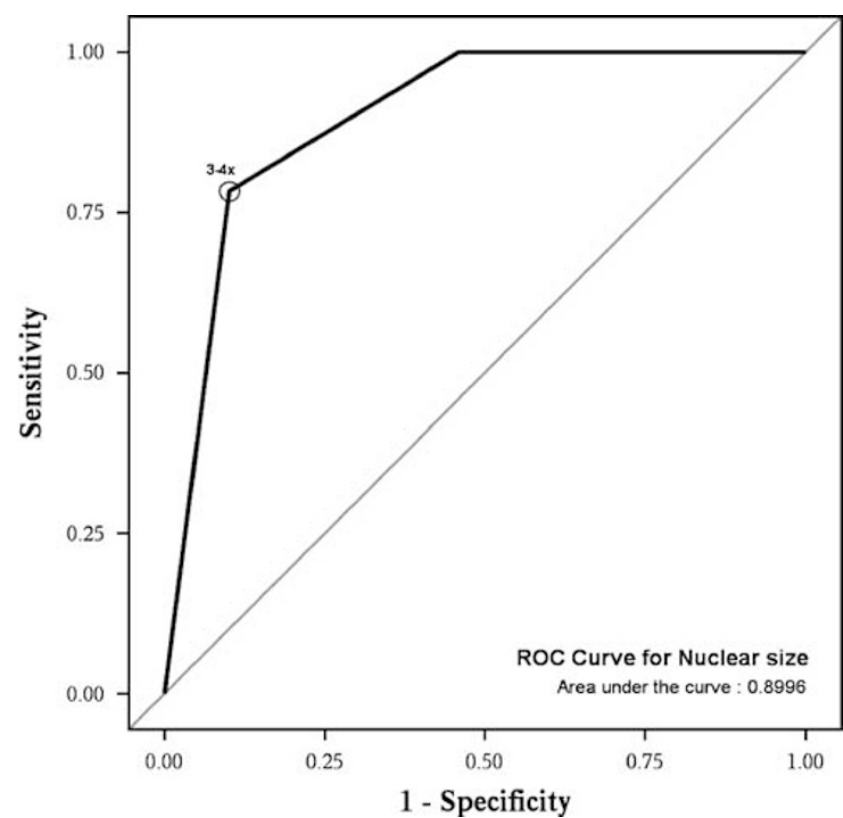

Figure 4 Receiver operator characteristic (ROC) curve, depicting the sensitivity relative to 1 -specificity with varying nuclear size cutoffs for distinguishing low- vs high-grade gastric-type dysplasia. The nuclear size cutoff of 3-4 times the size of a small mature lymphocyte is indicated on the curve.

needed to assist more accurate classification of Barrett's neoplasia.

The substantial per dysplastic biopsy (20\%) and per patient $(15 \%)$ prevalences seen in this series are highly relevant clinically, considering the complete lack of diagnostic criteria in the current literature, the significantly different morphology and criteria as presented herein, and the therapeutic consequences of a diagnosis of dysplasia, particularly high-grade dysplasia in Barrett's esophagus. ${ }^{10-12}$

The terms 'foveolar' or 'gastric-type dysplasia' are better recognized in the stomach itself, but even there only limited information is available. Dysplasia of the stomach has traditionally been categorized into the more common adenomatous or intestinaltype or type I dysplasia, and the less common gastric foveolar-type or non-adenomatous or type II dysplasia. ${ }^{13-19}$ Intestinal-type dysplasia, whether in the stomach or Barrett's esophagus, is characterized by variable villoglandular architecture and columnar cells with hyperchromatic, stratified, and enlarged nuclei, along with variable but typically inconspicuous nucleoli. The most objective and discriminatory criterion for separating low-grade and highgrade intestinal-type dysplasia is that of the loss of nuclear polarity. ${ }^{6,20}$ Maintenance of nuclear polarity refers to elongated, stratified, and pencillate nuclei that remain orderly and with the long axes of their nuclei perpendicular to the basement membrane, features typical of low-grade intestinal-type dysplasia. ${ }^{6}$ Alternatively, loss of nuclear polarity refers to loss of this orderly nuclear arrangement with the development instead of pleomorphic and disordered stratified nuclei that are no longer perpendicular to the basement membrane, features typical of high-grade intestinal-type dysplasia. ${ }^{6}$ Unfortunately, the criterion of the loss of nuclear polarity is not applicable to gastric-type dysplasia, because of its consistently non-stratified, monolayer nuclear arrangement at the polar base of the cells in both low- and high-grade gastric-type dysplasia (present in $100 \%$ of Barrett's gastric-type dysplasia in this cohort). This creates a diagnostic dilemma for the recognition of and grading of gastric-type Barrett's dysplasia using only traditional intestinal-type dysplasia criteria and was a major impetus to the establishment of better criteria for the gastric variant of dysplasia in Barrett's esophagus.

In addition to the monolayered nuclei, the remaining major characteristics of the gastric-type Barrett's dysplasia, regardless of grade, are fullthickness mucosal involvement (100\%), glandular rather than villiform growth pattern (94\%), prominent nucleoli (84\%), back-to-back crowded glandular architecture $(78 \%)$, and uniform rather than pleomorphic nuclear cytology $(65 \%)$.

The different grades of gastric-type Barrett's dysplasia are distinguished primarily by nuclear size and complexity of architecture. Nucleoli are prominent in all high-grade lesions, but about $40 \%$ of low-grade lesions lacked nucleoli in this study. Nuclear pleomorphism, although mild in degree, in general, in gastric-type dysplasia, was also a useful feature, being present in $13 \%$ of low-grade but $51 \%$ of high-grade gastric-type dysplasias $(P<0.001)$. The type of cytoplasm in Barrett's gastric-type dysplasia is variable, ranging from mucinous to oncocytic to eosinophilic. However, high-grade lesions are much more likely to have either eosinophilic or oncocytic cytoplasm than low-grade lesions (72 vs $30 \%$, $P<0.001)$. The cytoarchitectural criteria for grading Barrett's gastric-type dysplasia are summarized in Table 2.

In 2008, Asthana et $a l^{21}$ reported the first case of an extremely well-differentiated intramucosal adenocarcinoma of the gastric foveolar-type phenotype in Barrett's esophagus. The first small series of gastric-type dysplasia (non-adenomatous dysplasia) in Barrett's esophagus followed in 2009. ${ }^{4}$ This study emphasized DNA ploidy alterations in their limited cohort of 1 pure and 17 mixed gastric-type dysplasia patients followed over a 6 -year period, finding no significant differences in ploidy in comparison with conventional intestinal-type dysplasia controls. It can be noted that these authors reported a relatively similar per patient prevalence of gastric-type dysplasia, at $7 \%$ in comparison with our $15 \%$. Importantly, however, a grading scheme for gastrictype dysplasia was not provided by these authors, who did not further subdivide the low-grade dysplasia, high-grade dysplasia, or intramucosal adenocarcinoma subcategories. Our study is the first to address the diagnostic element of grade in gastrictype Barrett's dysplasia. 


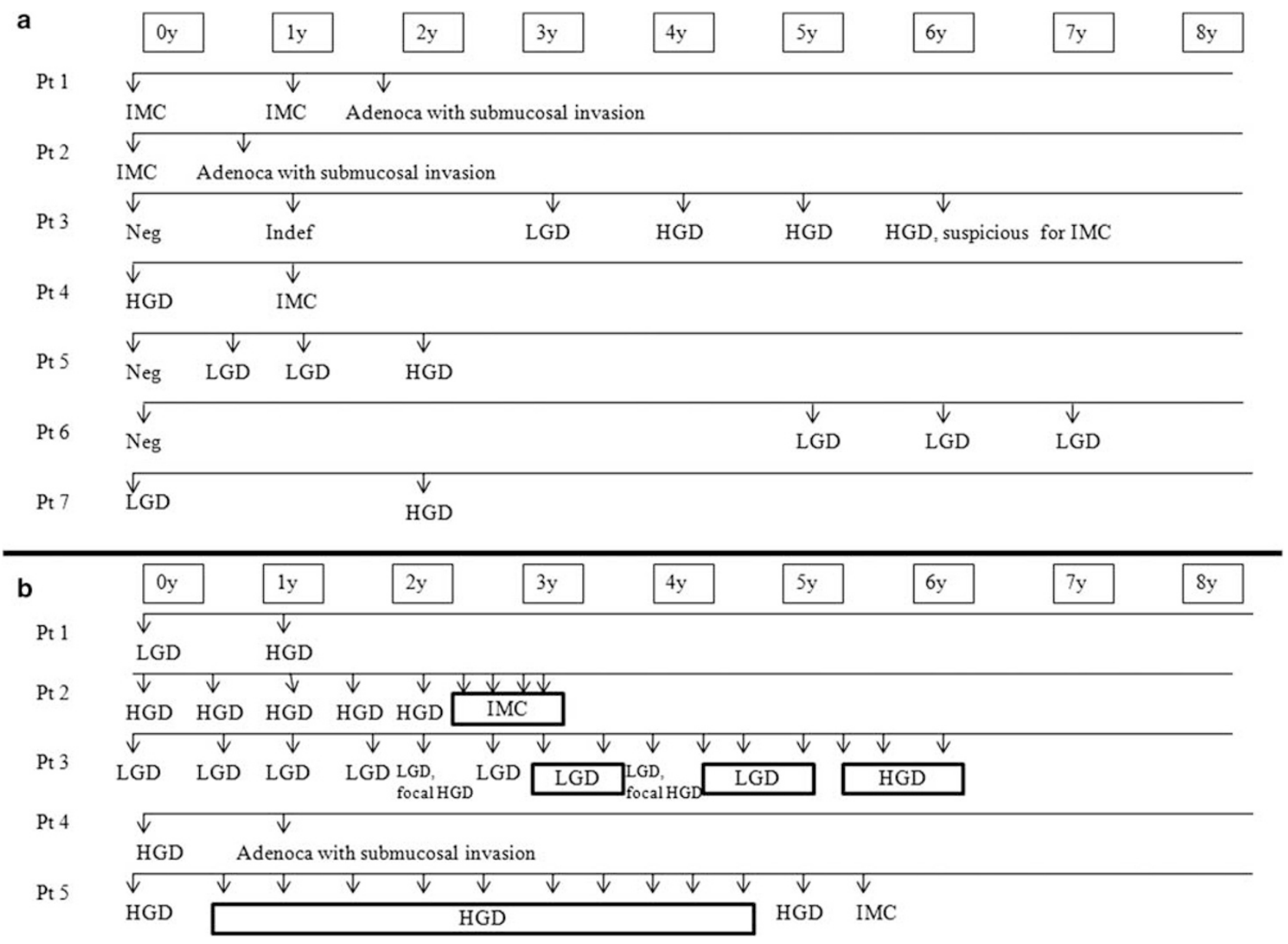

Figure 5 Longitudinal outcomes of Barrett's neoplasia in patients with (a) pure gastric-type dysplasia who progressed (64\%, 7 of 11 patients) and (b) mixed gastric and intestinal-type dysplasia who progressed (26\%, 5 of 19 patients).

Goblet cells were present in all 200 consecutive Barrett's dysplasia patients in this series (100\%). This further validates the use of goblet cells as the defining histological feature of Barrett's esophagus, regardless of the gastric or intestinal-type dysplasia that may arise from it. Gastric-type foveolar cells are present in the distal most esophageal epithelium in essentially all patients with gastroesophageal reflux disease (GERD) and are also present in Barrett's esophageal mucosa. ${ }^{22}$ This of course renders gastrictype mucosa completely nonspecific for defining Barrett's separately from GERD. This becomes even more problematic considering that reflux disease is at least 1000 times more common than Barrett's dysplasia or adenocarcinoma. Some might be tempted to misconstrue the concept of gastric foveolar-type dysplasia in Barrett's as evidence that Barrett's esophagus should also be redefined to include any type of glandular epithelium in the esophagus, including gastric type without goblet cells. This would be a serious error, based on the complete non-specificity of gastric mucosa for distinguishing GERD and Barrett's and the extremely high prevalence of GERD without a definable cancer risk. Barrett's most definitely contains gastric-type cells, which in turn generate the $7-15 \%$ per patient prevalence of gastric-type Barrett's dysplasia, but gastric-type epithelium cannot be used to define Barrett's esophagus. To do so would dilute the risk of esophageal adenocarcinoma from its already very limited level in Barrett's esophagus histologically defined by goblet cells to a level far below that necessary for effective cancer screening. Improved cancer screening in Barrett's mandates increased specificity to identify the highest risk patients, and not the greatly diminished specificity that would result from redefining Barrett's esophagus to include gastric mucosa only without goblet cells. Thus, the definition of Barrett's esophagus and the requirement for goblet cells must remain separate from the diagnosis of Barrett's gastric-type dysplasia.

The grade of gastric-type Barrett's dysplasia in our cohort of patients was more often high-grade dysplasia and/or intramucosal adenocarcinoma, which together made up $77 \%$ of Barrett's gastrictype vs $30 \%$ of Barrett's intestinal-type dysplasia at the patient level in this cohort. Furthermore, in 
Table 2 Diagnostic criteria for gastric-type dysplasia in Barrett's esophagus

\begin{tabular}{|c|c|c|}
\hline \multirow{2}{*}{$\begin{array}{l}\text { Gastric-type } \\
\text { dysplasia grade }\end{array}$} & \multicolumn{2}{|c|}{ Criteria } \\
\hline & Architecture & Cytology \\
\hline $\begin{array}{l}\text { Negative for } \\
\text { dysplasia }\end{array}$ & $\begin{array}{l}\text { Uncrowded glands within abundant lamina propria } \\
\text { Mucosal surface or top-heavy atypia in inflamed } \\
\text { cardiac mucosa signifies reactive/regenerative and } \\
\text { non-dysplastic change }\end{array}$ & $\begin{array}{l}\text { Regular non-stratified bland epithelial cell nuclei } \sim 1 \text { to } 1.5 \\
\text { times the size of a small mature lymphocyte } \\
\text { Absent to rare nucleoli } \\
\text { Mucinous cytoplasm }\end{array}$ \\
\hline Indefinite & $\begin{array}{l}\text { Partial to full-thickness mucosal involvement } \\
\text { Obscuring biopsy artifacts (small size, inflammatory } \\
\text { change, crush, inadequate histology preventing an } \\
\text { unequivocal diagnosis of dysplasia) }\end{array}$ & Same as low-grade dysplasia below + /-obscuring artifacts \\
\hline $\begin{array}{l}\text { Low-grade } \\
\text { dysplasia }\end{array}$ & $\begin{array}{l}\text { Full-thickness mucosal involvement } \\
\text { Uncrowded to crowded glands without villiform or } \\
\text { cribriform growth or dilated glands with luminal } \\
\text { debris }\end{array}$ & $\begin{array}{l}\text { Regular non-stratified epithelial cell nuclei that are } 2-3 \\
\text { times the size of a small mature lymphocyte } \\
\text { Variable but mild nuclear pleomorphism, if present at all } \\
\text { Variable nucleoli } \\
\text { Mucinous cytoplasm in the majority }\end{array}$ \\
\hline $\begin{array}{l}\text { High-grade } \\
\text { dysplasia }\end{array}$ & $\begin{array}{l}\text { Full-thickness mucosal involvement } \\
\text { Crowded glandular architecture with little to no } \\
\text { intervening lamina propria } \\
\text { Villiform growth, cribriform glands and dilated } \\
\text { glands containing luminal debris variably present }\end{array}$ & $\begin{array}{l}\text { Regular non-stratified epithelial cell nuclei that are } 3-4 \\
\text { times than the size of a small mature lymphocyte } \\
\text { Mild-to-moderate nuclear pleomorphism (note: marked } \\
\text { nuclear pleomorphism is rare in gastric-type dysplasia) } \\
\text { Regular nucleoli } \\
\text { Eosinophilic-to-oncocytic cytoplasm in the majority }\end{array}$ \\
\hline $\begin{array}{l}\text { Adenocarcinoma, } \\
\text { intramucosal }\end{array}$ & $\begin{array}{l}\text { Absence of stromal desmoplasia } \\
\text { Multiple single malignant cells invading the lamina } \\
\text { propria, or } \\
\text { Solid sheets of cells replacing the lamina propria, or } \\
\text { Abortive, angulated glands invading the lamina } \\
\text { propria, or } \\
\text { Never-ending glandular pattern invading the lamina } \\
\text { propria }\end{array}$ & $\begin{array}{l}\text { Same as high-grade dysplasia but may have more marked } \\
\text { nuclear pleomorphism }\end{array}$ \\
\hline $\begin{array}{l}\text { Adenocarcinoma, } \\
\text { submucosal }\end{array}$ & $\begin{array}{l}\text { Unequivocal stromal desmoplasia in combination } \\
\text { with any of the above invasive patterns }\end{array}$ & $\begin{array}{l}\text { Same as high-grade dysplasia but may have more marked } \\
\text { nuclear pleomorphism }\end{array}$ \\
\hline
\end{tabular}

patients with mixed dysplasia, we found that the gastric component often constituted the higher grade of dysplasia. These findings are similar to the one other series in the literature. ${ }^{4}$ Although tertiary care referral and reporting bias cannot be eliminated, and these diagnoses are definitional at this early stage of study, the high rates of reported neoplastic progression for these patients also support the contention that gastric-type Barrett's dysplasia can be aggressive and possibly even more aggressive than intestinal-type Barrett's dysplasia.

Another diagnostic dilemma for the pathologist concerns distinguishing reactive/inflamed but nondysplastic gastric cardiac mucosa from true gastrictype dysplasia. Gastric-type dysplasia shows fullthickness mucosal involvement, extending from the base of the mucosa to the surface. In contrast, gastric cardia with regenerative or inflammatory change typically reveals surface predominant or top-heavy atypia with relative sparing of the deeper glands at the base of the mucosa. This is likely due to the gastric neck or upper-mid location of the regenerative compartment in gastric mucosa. Regenerative atypia, therefore, also usually begins half-way or higher within gastric mucosa and extends to the surface with sparing of the basal glands. Thus, fullthickness mucosal atypia favors dysplasia and is among the most useful of criterion, in addition to the presence of obscuring active inflammation, for distinguishing reactive non-dysplastic epithelium from true gastric-type dysplasia.

In summary, gastric foveolar-type dysplasia comprises a minor but important histological subtype of dysplasia in Barrett's esophagus, involving $20 \%$ of biopsies and $15 \%$ of patients in this consecutive 200 patient Barrett's dysplasia cohort. New grading criteria were developed based on the systematic categorization of these biopsies. Histologically, the diagnosis and grading of gastric-type Barrett's dysplasia rely on very different criteria from intestinal-type dysplasia. The major differential aspect includes the non-stratified and basally oriented nuclei of gastric-type dysplasia. Accordingly, the distinguishing criterion of loss of nuclear polarity that helps to separate low- and high-grade intestinal-type dysplasia cannot be used for gastrictype dysplasia. Rather, low- and high-grade gastrictype dysplasia in Barrett's esophagus are distinguished by a nuclear size cutoff of 3-4 times the size of a small, mature lymphocyte, increased but still relatively mild nuclear pleomorphism, prominent nucleoli, increasingly eosinophilic to oncocytic cytoplasm, and crowded to irregular glandular architecture, all more common in high-grade gastric-type dysplasia. The natural history of foveolar gastric-type dysplasia remains poorly defined and is 
based on only 49 total patients in the composite literature at present, of which 30 are reported in this series. On the basis of these limited data, gastrictype dysplasia appears to be more often high-grade and occurs in increased numbers of women, in patients who on average are a decade older than those with intestinal-type Barrett's neoplasia. Longitudinal outcome data show neoplastic progression in $64 \%$ patients of pure gastric-type dysplasia and in $26 \%$ of mixed gastric-type dysplasia over the 8 years of follow-up in our series. Future longitudinal cohort studies will be essential to better determine the significance and rate of progression of gastrictype dysplasia in Barrett's neoplasia. This study provides diagnostic grading criteria for these future studies and for the improved routine diagnosis of Barrett's neoplasia.

\section{Disclosure/conflict of interest}

The authors declare no conflict of interest.

\section{References}

1 Montgomery E, Goldblum JR, Greenson JK, et al. Dysplasia as a predictive marker for invasive carcinoma in Barrett esophagus: a follow-up study based on 138 cases from a diagnostic variability study. Hum Pathol 2001;32:379-388.

2 Cameron AJ. Barrett's esophagus: does the incidence of adenocarcinoma matter? Am J Gastroenterol 1997;92:193-194.

3 Cameron AJ, Ott BJ, Payne WS. The incidence of adenocarcinoma in columnar-lined (Barrett's) esophagus. N Engl J Med 1985;313:857-859.

4 Rucker-Schmidt RL, Sanchez CA, Blount PL, et al. Nonadenomatous dysplasia in Barrett esophagus: a clinical, pathologic, and DNA content flow cytometric study. Am J Surg Pathol 2009;33:886-893.

5 Odze RD. Diagnosis and grading of dysplasia in Barrett's oesophagus. J Clin Pathol 2006;59:1029-1038.

6 Montgomery E, Bronner MP, Goldblum JR, et al. Reproducibility of the diagnosis of dysplasia in Barrett esophagus: a reaffirmation. Hum Pathol 2001;32:368-378.

7 Yachimski P, Nishioka NS, Richards E, et al. Treatment of Barrett's esophagus with high-grade dysplasia or cancer: predictors of surgical versus endoscopic therapy. Clin Gastroenterol Hepatol 2008;6:1206-1211.
8 Wang KK, Sampliner RE. Updated guidelines 2008 for the diagnosis, surveillance and therapy of Barrett's esophagus. Am J Gastroenterol 2008;103:788-797.

9 Downs-Kelly E, Mendelin JE, Bennett AE, et al. Poor interobserver agreement in the distinction of highgrade dysplasia and adenocarcinoma in pretreatment Barrett's esophagus biopsies. Am J Gastroenterol 2008;103:2333-2340.

10 Ireland AP, Clark GW, DeMeester TR. Barrett's esophagus. The significance of p53 in clinical practice. Ann Surg 1997;225:17-30.

11 Hamilton SR, Smith RR. The relationship between columnar epithelial dysplasia and invasive adenocarcinoma arising in Barrett's esophagus. Am J Clin Pathol 1987;87:301-312.

12 Hornick JL, Odze RD. Neoplastic precursor lesions in Barrett's esophagus. Gastroenterol Clin North Am 2007;36:775-796.

13 Abraham SC, Montgomery EA, Singh VK, et al. Gastric adenomas: intestinal-type and gastric-type adenomas differ in the risk of adenocarcinoma and presence of background mucosal pathology. Am J Surg Pathol 2002;26:1276-1285.

14 Abraham SC, Park SJ, Lee JH, et al. Genetic alterations in gastric adenomas of intestinal and foveolar phenotypes. Mod Pathol 2003;16:786-795.

15 Park do Y, Srivastava A, Kim GH, et al. Adenomatous and foveolar gastric dysplasia: distinct patterns of mucin expression and background intestinal metaplasia. Am J Surg Pathol 2008;32:524-533.

16 Park do Y, Lauwers GY. Gastric polyps: classification and management. Arch Pathol Lab Med 2008;132: 633-640.

17 Srivastava A, Lauwers GY. Gastric epithelial dysplasia: the Western perspective. Dig Liver Dis 2008;40: 641-649.

18 Goldstein NS, Lewin KJ. Gastric epithelial dysplasia and adenoma: historical review and histologic criteria for grading. Hum Pathol 1997;28:127-133.

19 Lauwers GY, Srivastava A. Gastric preneoplastic lesions and epithelial dysplasia. Gastroenterol Clin North Am 2007;36:813-829.

20 Bronner MP, Overholt BF, Taylor SL, et al. Squamous overgrowth is not a safety concern for photodynamic therapy for Barrett's esophagus with high-grade dysplasia. Gastroenterology 2009;136:56-64.

21 Asthana N, Mandich D, Ligato S. Esophageal polypoid dysplasia of gastric foveolar phenotype with focal intramucosal carcinoma associated with Barrett's esophagus. Am J Surg Pathol 2008;32:1581-1585.

22 Chandrasoma P. Controversies of the cardiac mucosa and Barrett's oesophagus. Histopathology 2005;46: 361-873. 